\title{
Economics of Hybrid Rice Cultivation in Northern Hill Zone of Chhattisgarh
}

\author{
Sunil Kumar Singh
}

Raj Mohini Devi College of Agriculture \& Research Station (RMD CARS), Indira Gandhi Agricultural University, Ambikapur, Surguja, Chhattisgarh-497001, India

Corresponding author: sunilndri@gmail.com

\begin{abstract}
North hill region is the major rice producing belt of Chhattisgarh. Northern hill region contributes about twelve per cent of total production of rice in the state. Adoption of hybrid rice constitutes a major component in the rise in productivity of rice in the state. Farmers found it more profitable than other crops due to high yield. Keeping the importance and potential of hybrid rice in the state, the presented study was undertaken. In the presented study, investigator tried to understand the socio-economic profile of the rice cultivators, costs and returns from hybrid rice cultivation and disposal pattern of rice in the study area. A sample of fifty farmers from study area was selected using simple random sampling technique. The size of family was found large (six family member) and majority of farmers are either literate or had attained higher education. The agriculture was found to be the main source of income of farmers in the study area. The cost of cultivation of hybrid rice was highest for large farmers and lowest for small farmers while return from rice cultivation was highest for marginal farmers and found lowest for small farmers despite the lowest cost of cultivation. The input-output ratio was found highest for medium farmers followed by marginal farmers. Majority of farmers sell their rice to government agencies followed by consumers and private agencies.
\end{abstract}

Keywords: Hybrid rice, Northern Hill Zone, Costs, Returns, Marketing

The term "hybrid rice" refers to the first-generation (F1) offspring of a cross of two genetically diverse parents that yields (performs) better than both parents due to manifestation of a biological phenomenon known as hybrid vigour or heterocyst. Farmers can benefit from hybrids if the F1 (hybrid) seeds are used for commercial cultivation; the grains produced on the commercial hybrid crop are unusable as seed for the next crop because, in the subsequent generations, the yield advantage expressed in the first generation offspring of a hybrid is significantly reduced due to inbreeding depression. Hybrid rice has the potential to increase the yields of rice globally (Yuan et al. 2000). The first cultivation of hybrid rice was carried out in China in 1976 yielded twenty per cent more output than conventional varieties of rice (Yuan, 2004; Quayum, 2006). Hybrid rice not only has a distinct yield advantage over conventional varieties but also is more responsive to fertilizer and can adapt to varying environments (Khushk et al. 2011). High-yield crops, like hybrid rice, are one of the most important tools for combating world food crises (IRRI). In India, in 2008, hybrid rice occupied 1.4 million hectares of area and contributed additional rice production of about 1.5 to 2.5 million tons (Department of Cooperation, Ministry of Agriculture\& Farmers Welfare, Government of India). In the development of hybrid rice for increasing production and supply of rice, conventional and biotechnological techniques should be used to develop such variety that must passes resistance against diseases and stress (Khush, 2005). There are evidences to show that farmers cultivating hybrid rice realized higher yield gains over conventional varieties in similar agro-climatic zones (Janaiah, 2003). Hybrid rice provides high profit due to increased productivity despite higher cost on account of higher seed prices, 
slightly higher land management costs (Wagan et al. 2015; Deliberto et al. 2010; Singh et al. 2013).

Rice is the major crop in Chhattisgarh. It is grown in both autumn and summer season in the state. Traditionally, rice was cultivated under rainfed condition in the state. But, the rice is being cultivated under irrigated condition as the economic benefit accruing to the farmer is more than the costs of creating irrigation facility. The gross cropped area under rice in Chhattisgarh is 4035700 ha (2014-15). Chhattisgarh is also known as bowl of rice due to intensive cultivation of rice in the state. Rice constitutes the major part of the food basket of people of Chhattisgarh. There is a significant improvement in production and productivity of rice in Chhattisgarh. This increase in rice production in state is due to adoption of hybrid rice. The cultivation of hybrid rice in the state changed tremendously after 2010 (Agricultural Statistics at a Glance 2015). Surguja is the largest producer of rice in Northern Hill Zone. The area under rice cultivation in Surguja district is 117268 ha which is the highest among the district of Northern hill region. The cultivation of hybrid rice is highest in the district. Keeping this in view, the Surguja district was selected for the study.

\section{METHODOLOGY}

The Chhattisgarh is divided into three Agro-climatic zones viz., Northern Hill Zone, Chhattisgarh Plains Zone and Baster Plateau Zone. The Northern Hill Zone is composed of five districts namely Balrampur, Surguja, Jashpur, Surajpur and Korea. The Surguja district produces highest amount of rice among five districts of this zone. The data for the study was collected from Surguja district. Two blocks namely Lundra and Btauli were selected due the intensive cultivation of hybrid rice in these blocks. Three villages namely, Kakani, Dadgaon and Batwahi were selected from Lundra block and two villages namely, Tirang and Maheshpur were selected from Batauli block. Simple random sampling was employed for selection of sampled farmers. Total of fifty hybrid rice grower (ten from Kakani, ten from Dadgaon, eleven from Batwahi, ten from Tirang and nine from Maheshpur) from different size of land holding had been selected from the selected villages.

Data on operational land holdings, size of family, education of head of family and other family members, their age and gender; sources of income and various components of costs viz., expenditure on human, bullock and machine labour, seed, fertilizers, irrigation, insecticides \& pesticides and disposal of rice produced by the farmers were collected using well-structured pre-tested schedule. The tabular analysis had been employed for analysing the collected data.

\section{Sample Size}

Table 1: Number of sampled household and average size of land holding

\begin{tabular}{|c|c|c|c|c|c|}
\hline 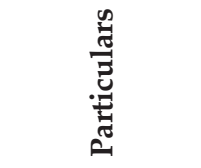 & 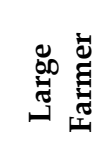 & 祸 & 苞 & 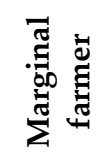 & $\begin{array}{l}\text { ప } \\
\text { อ }\end{array}$ \\
\hline $\begin{array}{c}\text { Sampled } \\
\text { household }\end{array}$ & 07 (14) & 09 (18) & $17(34)$ & $17(34)$ & $50(100)$ \\
\hline $\begin{array}{l}\text { Size of op. } \\
\text { land holding } \\
\text { (ha) }\end{array}$ & 5.17 & 2.43 & 1.14 & 0.44 & 2.30 \\
\hline
\end{tabular}

Figures in parentheses indicate percentage to overall.

The selected farmers from which data were collected comprised of seventeen marginal farmers, seventeen small farmers, nine medium farmers and seven large farmers as presented in Table 1.

\section{RESULTS AND DISCUSSION}

Area under rice cultivation and extent of irrigation across different Agro-Climatic Zones of Chhattisgarh:

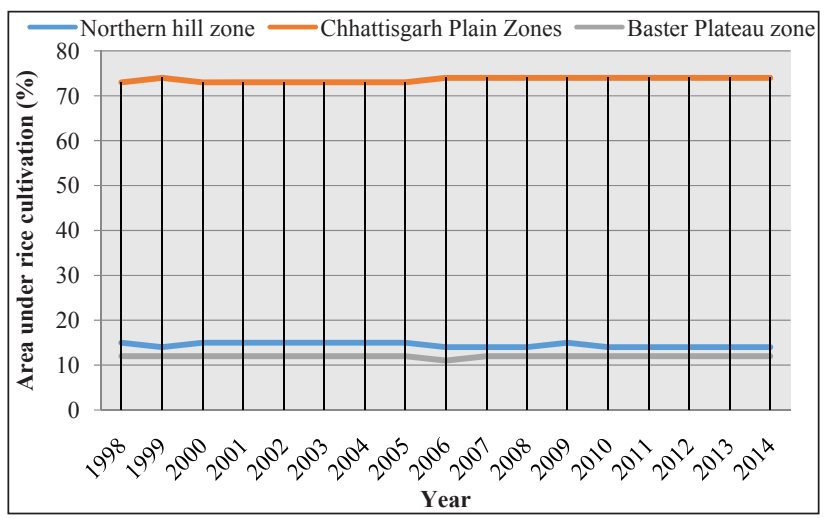

Fig. 1: Area under rice cultivation across different AgroClimatic Zones

The total area under rice cultivation is scattered among the three agro-climatic zones of the state. The area under rice cultivation, extent of irrigation 
across different agro-climatic zones and area under hybrid rice cultivation is shown in Fig. 1, 2 and 3, respectively. As per the Fig. 1, the largest area under rice cultivation was found to be occupied by Chhattisgarh Plains Zone followed by Northern Hill Zone and Baster Plateau Zone. The irrigated area under rice cultivation in Chhattisgarh Plains Zone was found to be 47 per cent while in Northern Hill Zone and Baster Plateau Zone, it was found to be 3 per cent and 1 per cent respectively as indicate in Fig. 2. As per the Fig. 3, there was a massive change in the area under hybrid rice after 2010-11. This change in area under hybrid rice was not induced by any government efforts but by the farmers due to the high returns from hybrid rice.

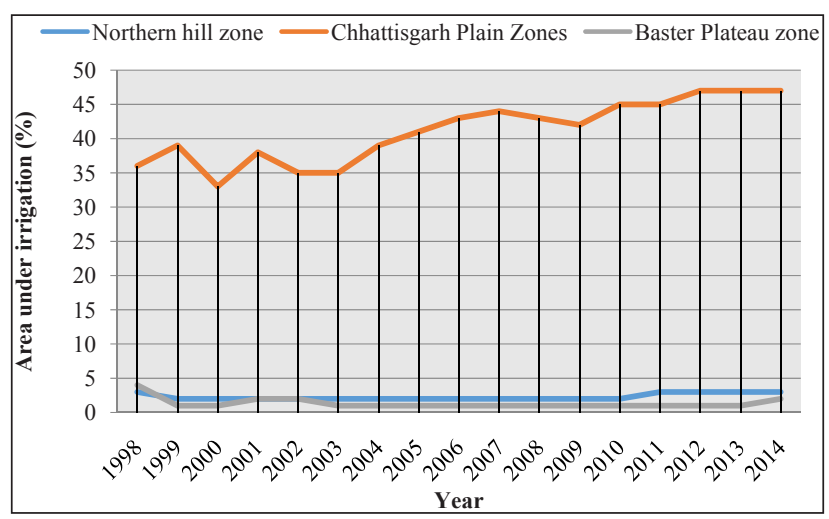

Fig. 2: Area under irrigation across different Agro-Climatic Zones

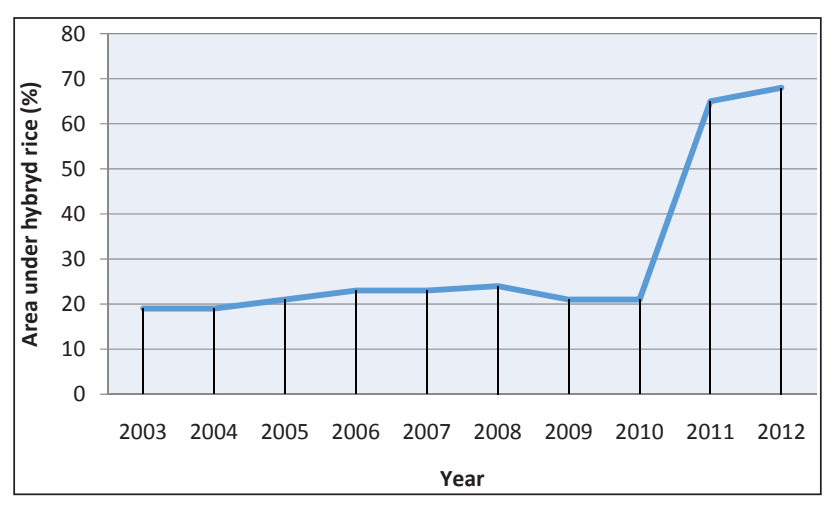

Fig. 3: Area under hybrid rice cultivation in Chhattisgarh

The high returns from hybrid rice due to high productivity motivated the farmers for adoption of this crop. To catch the rising demand of hybrid rice seeds, private agricultural inputs producing companies like Syngenta, VNR, Adventa, Bayer, etc., jumped in. These companies raised the pace of adoption of hybrid rice in the state by increasing the supply of seeds. The Northern Hill Zone is one of the highest adopter of hybrid rice as most of the farmers in this region cultivate hybrid rice. Rice is the main crop and cultivated in two season viz., autumn and summer. The rice is cultivated in rainfed condition in the Northern Hill Zone and Baster Plateau Zone as the majority of irrigated area under rice is covered by Chhattisgarh Plains Zone. The irrigation facility is very poor in Northern Hill Zone as irrigated area under rice is only three per cent. The, overall, one third of area under rice cultivation in the state is covered with irrigation facilities and rest are un-irrigated.

\section{Family size}

The family size of the sampled households is presented in table 2. The average size of family was found to be 5.94 comprising 3.08 male and 2.86 female as indicated by the table 2 . The size of family was found highest for large farmer and it was lowest for small farmer.

Table 2: Average family size

\begin{tabular}{cccccc}
\hline \multirow{2}{*}{$\begin{array}{c}\text { Composition } \\
\text { of family }\end{array}$} & \multicolumn{5}{c}{ Land holding category } \\
\cline { 2 - 6 } & $\begin{array}{c}\text { Marginal } \\
\text { farmer }\end{array}$ & $\begin{array}{c}\text { Small } \\
\text { Farmer }\end{array}$ & $\begin{array}{c}\text { Medium } \\
\text { farmer }\end{array}$ & $\begin{array}{c}\text { Large } \\
\text { Farmer }\end{array}$ & Overall \\
\hline Male & 3.41 & 2.12 & 3.22 & 3.57 & 3.08 \\
Female & 2.59 & 2.24 & 2.89 & 3.71 & 2.86 \\
\hline Total & $\mathbf{6}$ & $\mathbf{4 . 3 5}$ & $\mathbf{6 . 1 1}$ & $\mathbf{7 . 2 9}$ & $\mathbf{5 . 9 4}$ \\
\hline
\end{tabular}

\section{Educational status of sampled households}

The educational status of sampled households is given in table 3 . The table 3 indicated that twenty six per cent of the sampled cultivars were found illiterate and remaining selected farmers were either literate or had attained higher level of education.

Table 3: Educational status of selected farmers

\begin{tabular}{|c|c|c|c|c|c|}
\hline \multirow{2}{*}{$\begin{array}{l}\text { Level of } \\
\text { education }\end{array}$} & \multicolumn{4}{|c|}{ Land holding category } & \multirow[b]{2}{*}{ Overall } \\
\hline & $\begin{array}{c}\text { Marginal } \\
\text { farmer }\end{array}$ & $\begin{array}{c}\text { Small } \\
\text { Farmer }\end{array}$ & $\begin{array}{c}\text { Medium } \\
\text { farmer }\end{array}$ & $\begin{array}{l}\text { Large } \\
\text { Farmer }\end{array}$ & \\
\hline Illiterate & $4(23.53)$ & $3(17.65)$ & $4(44.44)$ & $2(28.57)$ & $13(26)$ \\
\hline Literate & $6(35.59)$ & $3(17.65)$ & $1(11.11)$ & - & $10(20)$ \\
\hline $\begin{array}{l}\text { Up to } 8^{\text {th }} \\
\text { class }\end{array}$ & $4(23.53)$ & $7(41.18)$ & $2(22.22)$ & $2(28.57)$ & $15(30)$ \\
\hline $\begin{array}{c}12^{\text {th }} \text { and } \\
\text { above }\end{array}$ & $3(17.65)$ & $4(23.52)$ & $2(22.22)$ & $3(42.86)$ & $12(24)$ \\
\hline Total & $17(100.00)$ & $17(100.00)$ & $9(100.00)$ & $7(100.00)$ & $50(100)$ \\
\hline
\end{tabular}

Figures in parentheses indicates percentage to total. 


\section{Source of income}

The various sources from which farmer derive their income are given in the Table 4. As per Table 4, the ninety two percent of sampled households was deriving their main income from agriculture and remaining eight percent household's main source of income was found to be services.

Table 4: Major source of income of sampled household

\begin{tabular}{cccccc}
\hline \multirow{2}{*}{$\begin{array}{c}\text { Major } \\
\text { occupation }\end{array}$} & \multicolumn{5}{c}{ Land holding category } \\
\cline { 2 - 5 } & $\begin{array}{c}\text { Marginal } \\
\text { farmer }\end{array}$ & $\begin{array}{c}\text { Small } \\
\text { Farmer }\end{array}$ & $\begin{array}{c}\text { Medium } \\
\text { farmer }\end{array}$ & $\begin{array}{c}\text { Large } \\
\text { Farmer }\end{array}$ & Overall \\
\hline Agriculture & 17 & 16 & 9 & 4 & 46 \\
& $(100.00)$ & $(94.12)$ & $(100.00)$ & $(57.14)$ & $(92.00)$ \\
Services & - & $1(5.88)$ & - & $3(42.86)$ & $4(8.00)$ \\
Others & - & - & - & - & - \\
\hline \multirow{2}{*}{ Total } & $\mathbf{1 7}$ & $\mathbf{1 7}$ & $\mathbf{9}$ & $\mathbf{7}$ & $\mathbf{5 0}$ \\
& $\mathbf{( 1 0 0 . 0 0 )}$ & $\mathbf{( 1 0 0 . 0 0 )}$ & $\mathbf{( 1 0 0 . 0 0 )}$ & $\mathbf{( 1 0 0 . 0 0 )}$ & $\mathbf{( 1 0 0 . 0 0 )}$ \\
\hline
\end{tabular}

Figures in parentheses indicate percentage to total.

\section{Cost and returns from hybrid rice cultivation}

The costs and returns from hybrid rice cultivation are shown in Table 5. The average cost of cultivation of hybrid rice was found to be ₹ 40062.07. Labour cost and rental value of own land was found to be major component of cost of cultivation accounting for 35.25 per cent and 24.96 per cent of total costs, respectively. The cost of cultivation were found to be highest for large farmers ( $₹$ 43452.57) due to high expenditure on fixed assets like tractor, seed drill and other farm machinery \& equipments and it was lowest for small farmers ( $₹$ 38315.69). The average gross return were found to be $₹ 69480.09$ which was highest for marginal farmers (₹ 71058.82) possibly due to efficient utilisation of resources and better managerial skills as they have to fulfil their family requirement from tiny piece of land they owned and lowest for small farmers ( $₹$ 65560.20). The average net returns were found to be ₹ 29418.02, which was highest for marginal farmers (₹ 31532.26) and lowest for small farmers (₹ 27244.51). The overall

Table 5: Costs and returns from cultivation of hybrid rice (₹/hectare)

\begin{tabular}{cccccc}
\hline \multirow{2}{*}{ Cost component } & \multicolumn{5}{c}{ Land holding category } \\
\cline { 2 - 6 } & Marginal farmer & Small Farmer & Medium farmer & Large Farmer & Overall \\
\hline Total labour & $13450.29(34.03)$ & $13847.94(36.14)$ & $14382.78(36.92)$ & $14799.29(36.06)$ & $14120.07(35.25)$ \\
Seed & $4117.65(10.42)$ & $4102.94(10.71)$ & $4166.67(10.70)$ & $4321.43(9.95)$ & $4177.17(10.43)$ \\
Manure & $3000(7.59)$ & $3000(7.83)$ & $3000(7.70)$ & $3000(6.90)$ & $3000(7.49)$ \\
Fertilizer & $3000(7.59)$ & $3000(7.83)$ & $3000(7.70)$ & $3000(6.90)$ & $3007.490(7.50)$ \\
Exp. On insecticide & $1500(3.79)$ & $1200(3.13)$ & $1000(2.57)$ & $1000(2.30)$ & $1175(2.93)$ \\
Irrigation & $110(0.28)$ & $82.35(0.21)$ & $133.33(0.37)$ & $114.29(0.26)$ & $109.99(0.27)$ \\
Land Revenue & - & - & - & - & - \\
Rent paid for leased-in & - & - & - & - & - \\
land & $1198.83(3.03)$ & $510.61(1.33)$ & $593.89(1.52)$ & $2701.43(6.22)$ & $1251.19(3.12)$ \\
Depreciation & $10000(25.30)$ & $10000(26.10)$ & $10000(25.67)$ & $10000(23.01)$ & $10000(24.96)$ \\
Rental value of own land & & & & & \\
Interest on Working & $2130.78(5.39)$ & $2137.83(5.58)$ & $2171.7(5.58)$ & $2220.26(5.28)$ & $2165.14(5.40)$ \\
Capital & $1019.01(2.58)$ & $434.02(1.13)$ & $504.81(1.30)$ & $2296.21(5.11)$ & $1063.51(2.65)$ \\
Interest on Fixed Capital & $39526.56(100.00)$ & $38315.69(100.00)$ & $38953.18(100.00)$ & $43452.91(100.00)$ & $40062.07(100.00)$ \\
Total Cost & 66352.94 & 61293.53 & 65800 & 66068.57 & 64878.76 \\
Main product & 4705.88 & 4266.67 & 4666.67 & 4685.71 & 4601.33 \\
By Product & 71058.82 & 65560.20 & 70466.67 & 70754.29 & 69480.09 \\
Gross returns & 31532.26 & 27244.51 & 31513.49 & 27301.38 & 29418.02 \\
Net returns & 1.80 & 1.71 & 1.81 & 1.63 & 1.73 \\
I-O ratio & & & &
\end{tabular}

Figures in parentheses indicates percentage to total cost. 
input-output ratio was found to be 1.73 which was highest for medium farmers (1.81) and lowest for large farmers (1.63).

\section{Marketing of rice}

The rice produced by sampled households is marketed through various agencies. The agencies to which rice was sold are presented in table 6 . Only seventy six per cent of sampled households reported that they sale rice produced by them. The rice produced by farmers was sold to government agency, private agency and directly to the consumers. The share of farmers selling their rice to the government agency, private agency and directly to the consumer were found to be forty seven, twenty four and twenty nine per cent, respectively.

Table 6: Disposal pattern of rice by the farmers

\begin{tabular}{|c|c|c|c|c|c|}
\hline \multirow{2}{*}{$\begin{array}{l}\text { Sold to } \\
\text { whom }\end{array}$} & \multicolumn{5}{|c|}{ Land holding category } \\
\hline & $\begin{array}{c}\text { Marginal } \\
\text { farmer }\end{array}$ & $\begin{array}{c}\text { Small } \\
\text { Farmer }\end{array}$ & $\begin{array}{c}\text { Medium } \\
\text { farmer }\end{array}$ & $\begin{array}{c}\text { Large } \\
\text { Farmer }\end{array}$ & Overall \\
\hline $\begin{array}{c}\text { Government } \\
\text { agency }\end{array}$ & $5(29.4)$ & $7(64.0)$ & $4(67.0)$ & $2(50.0)$ & $\begin{array}{c}18 \\
(47.0)\end{array}$ \\
\hline $\begin{array}{l}\text { Private } \\
\text { agency }\end{array}$ & $6(35.3)$ & $2(18.0)$ & - & $1(25.0)$ & $9(24.0)$ \\
\hline Consumer & $6(35.3)$ & $2(18.0)$ & $2(33.0)$ & $1(25.0)$ & $\begin{array}{c}11 \\
(29.0) \\
\end{array}$ \\
\hline Total & $17(100)$ & $11(100)$ & $6(100)$ & $4(100)$ & $38(100)$ \\
\hline
\end{tabular}

Figures in parentheses indicate percentage to total.

\section{CONCLUSION}

Rice is the main crop of Chhattisgarh with respect to production and consumption. Rice is grown in both autumn and summer season. Majority of area under rice cultivation comes under Chhattisgarh Plains Zone with the irrigation facilities covering forty seven per cent of total area under rice cultivation in this zone. In Northern Hill Zone, rice is cultivated under rain-fed condition as very tiny area is covered with irrigation facilities. The hybrid rice is cultivated on majority of land under Northern Hill Zone. Surguja is the major rice producing district in the Northern Hill Zone and hybrid rice is cultivated intensively in this district. The size of family is large as the common feature of under developed region. Majority of rice grower is either literate or had attained higher education which helps them in making better decision on farm. The cost of cultivation of rice in this region is high. The major components of costs were expenditure on labour (human, bullock and machine labour) and rental value of owned land. The medium farmers are more efficient in decision making on organisation and operation of farm for rice production as reflected by low cost and high returns on farm. This efficiency may be induced by the better knowledge and availability of resources for rice cultivation. The majority of farmers market their rice through government agencies followed by consumer and private agencies. The major source of income is agriculture. The unique blend of modern and traditional techniques of rice cultivation can be seen in this region as some farmers use modern machinery and equipment like tractor, seed drill, etc., while other use traditional means like bullock for ploughing the field and other purposes for rice cultivation.

\section{ACKNOWLEDGEMENTS}

The researcher is very thankful to the ViceChancellor of Indira Gandhi Agricultural University, Raipur for providing fund for the project. Researcher is also thankful to those farmers and other people who had, directly or indirectly, participated in the survey and provided valuable information without which, this study could not be completed.

\section{REFERENCES}

Agricultural Statistics at a glance (various issues), Directorate of Economics \& Statistics, Department of Cooperation, Ministry of Agriculture \& Farmer Welfare, Government of India.

Chengappa, P.G., Janaiah, A. and Gowda, M.V. S. 2003. Profitability of hybrid rice cultivation evidence from Karnataka. Economic and Political Weekly, 38(25): 2531-2534.

Deliberto, M.A. and Salassi, M.E. 2010. Hybrid rice production costs and returns: comparisons with conventional \& Clearfield varieties, Staff Report No. 06.

Guidelines for seed production of hybrid rice, National Food Security Mission, Department of Cooperation, Ministry of Agriculture \& Farmer Welfare, Government of India.

International Rice Research Institute (IRRI). http://www.irri. org.

Khushik, A.M., Lashari, M.I. and Memon, A. 2011. Performance of rice hybrid and other varieties in Sindh and Balochistan. Journal of Agricultural Research, 49(4): 561-570.

Quayum, M.A., Mustafi, B.A.A. and Baset, M.A. 2006. Economics of Irrigated rice cultivation in selected areas of Bangladesh. Journal of Agricultural Research, 21(1): 07-08. 
Singh, H.N., Singh, S., Singh, U.N., Zaidi, N.W. \& Mohanty, S. 2013. Economic evaluation of Pusa Rice Hybrid 10 cultivation: A micro-economic evidence from Utterakhand. India. Indian Journal of Tradition Knowledge, 12(3): 472-477.

Wagan S.A., Noonari S., Memon., I.N., Bhatti M.A., Kalwar G.Y., Sethar A.A. and Jamro A.S. 2015. Comparative
Economic Analysis of Hybrid Rice v/s Conventional Rice Production in District Badin Sindh Province, Pakistan. Journal of Environment and Earth Science, 5(3): 76-89.

Yuan, L. 2004. Hybrid rice technology for food security in the world. The World Food Prize International Symposium. 